\title{
SIMULAÇÃO COMPUTACIONAL DA CARCAÇA METÁLICA INFERIOR DO FORNO ELÉTRICO A ARCO DA SIDERÚRGICA SINOBRAS S.A*
}

\author{
Allison de Sá Barreto Ferreira ${ }^{1}$ \\ Vinícius dos Santos Gonçalves ${ }^{2}$ \\ Neiclesio Nunes Ibiapina ${ }^{3}$ \\ Márcio Corrêa de Carvalho ${ }^{4}$ \\ Gerson Ceslau Rusky ${ }^{5}$
}

\begin{abstract}
Resumo
O objetivo deste trabalho consiste em estudar o perfil térmico da carcaça metálica inferior do Forno Elétrico a Arco (FEA) durante o processo de produção de aço, sugerindo adição de aletas na geometria a fim de obter maior troca de calor e diminuição na temperatura de trabalho da carcaça metálica inferior do FEA. Assim, analisou-se a influência do ciclo térmico do processo por meio de acompanhamento termográfico e simulações computacionais via Método de Elementos Finitos. Posto isto, as modificações propostas, depois de testadas e analisadas por meio de um acompanhamento termográfico, denotaram eficiência de tal maneira que resultou em uma diminuição de aproximadamente $60^{\circ} \mathrm{C}$ da temperatura na carcaça metálica inferior do FEA.
\end{abstract}

Palavras-chave: Forno elétrico a arco; Simulação computacional; Ciclo térmico; Aletas.

\section{COMPUTATIONAL SIMULATION OF THE LOWER METAL HOUSING OF THE ELECTRIC ARC FURNACE OF STEELMAKING SINOBRAS S.A}

\begin{abstract}
The objective of this work is to study the thermal profile of the lower metal housing of the Electric Arc Furnace (EAF) during the steel production process, suggesting the addition of fins in the geometry in order to obtain greater heat exchange and decrease in the working temperature of the lower metal housing of the EAF. Thus, the influence of the thermal cycle of the process was analyzed through thermographic monitoring and computational simulations using the Finite Element Method. Therefore, the proposed modifications, after being tested and analyzed by means of a thermographic monitoring, denoted efficiency in such a way that it resulted in a decrease of approximately $60^{\circ} \mathrm{C}$ in the temperature in the lower metal housing of the EAF.

Keywords: Electric arc furnace; Computer simulation; Thermal cycling; Fins.

1 Engenharia Mecânica, Graduando, Estagiário, Aciaria, Siderúrgica Norte Brasil (Sinobras S.A), Marabá, Pará e Brasil.

2 Engenharia Mecânica, Graduando, Estagiário, Aciaria, Siderúrgica Norte Brasil (Sinobras S.A), Marabá, Pará e Brasil.

3 Engenharia Química, Doutor, Docente, Instituto de Geociências e Engenharias/Faculdade de Engenharia de Materiais, Universidade Federal do Sul e Sudeste do Pará (Unifesspa), Marabá, Pará e Brasil.

4 Engenharia de Materiais, Graduado, Engenheiro de Processos, Aciaria, Siderúrgica Norte Brasil (Sinobras S.A), Marabá, Pará e Brasil.

5 Engenharia Metalúrgica, Graduado, Gerente Executivo Industrial, Aciaria, Siderúrgica Norte Brasil (Sinobras S.A), Marabá, Pará e Brasil.
\end{abstract}




\section{INTRODUÇÃO}

Atualmente 35\% do aço mundial são fundidos em Fornos Elétricos a Arco (FEAs) [1]. Os FEAs utilizados em aciarias para a fusão da sucata metálica representam, sem dúvida, o instrumento mais versátil de produção de aço, e vêm se tornando também, nas últimas décadas, um dos mais eficientes [2].

As altas temperaturas de trabalho do FEAs são alvos de análises constantes. Um acompanhamento térmico, muitas vezes por instrumentos de medições como pirômetros e câmeras termográficas, é de primordial importância para o processo de produção. Tal indicador permite tomada de ações rápidas e necessárias para esquivar-se de prováveis paradas no processo. Uma situação usual, diz respeito quanto às altas temperaturas da carcaça inferior do FEA, principalmente em final de campanha quando o refratário já está bastante gasto, o que indica a necessidade de reparo na região, muitas vezes através de projeções de massas refratárias. Assim, evitando-se maiores consequências, como, por exemplo, a perfuração da carcaça metálica causando grandes paradas para reparo e possíveis acidentes graves, devido o vazamento de aço líquido.

Deste modo, é imprescindível o controle do ciclo térmico que ocorre durante o processo de fusão e refino do aço para a obtenção de uma carcaça isenta de perfurações e vazamentos. [3]

Por outro lado, a utilização de aletas para potencializar a eficiência na troca de energia na forma de calor tem sido um procedimento comum utilizado há várias décadas [4]. As aletas são superfícies que se estendem de um objeto com a finalidade de aumentar sua troca térmica com o ambiente a partir de trocas de calor por convecção e radiação. Pode-se aumentar a taxa de transferência de calor de um corpo através do aumento de $h$ (coeficiente de transferência de calor por convecção) com o uso de sistemas que aumentem a velocidade do fluido que escoa na sua superfície ou que diminuam a temperatura do mesmo. Porém, soluções como estas podem ter custos muito elevados, tornando-as inviáveis. Por este motivo, a forma mais utilizada de prover o crescimento da taxa de transferência é através do aumento da área [5].

Assim, o presente trabalho tem como objetivo analisar, através da coleta de dados na área, simulações computacionais e cálculos analíticos, o perfil térmico da carcaça metálica inferior do FEA durante o processo de produção de aço, sugerindo adição de aletas na geometria a fim de obter maior troca de calor e diminuição na temperatura de trabalho da carcaça.

$\mathrm{Na}$ direção radial de cada eletrodo de grafite no FEA, há um setor chamado "ponto quente" onde ocorre maior radiação e aquecimento [6]. Assim, o setor utilizado como referencial para a comparação entre as analises termográficas e as simulações computacionais foi o ponto quente 4, ilustrado na Figura 1. Além disso, tal região possui fácil acesso e um histórico de problemas como avermelhamentos e perfurações da chapa metálica. Alcançando o objetivo citado deve-se, por consequência, melhorar o desempenho desta região, abaixando sua temperatura de trabalho evitando avermelhamentos e grandes deformações térmicas.

\section{MATERIAIS E MÉTODOS}

\subsection{Determinação das temperaturas de trabalho da carcaça metálica inferior do FEA}

O controle da temperatura dos processos em uma aciaria é de fundamental importância para se atingir os requisitos de qualidade e produtividade exigidos 
atualmente. Mediante ao auxílio da câmera termográfica FLIR - Série T foi possível obter dados da temperatura externa da carcaça metálica inferior do FEA em diversos pontos. Foram analisadas 480 termografias referentes à campanha de junho de 2016 em 13 pontos distribuídos ao redor da carcaça, Figura 1 (b). Todas as medidas foram tiradas de planilhas eletrônicas de controle de processo e a média da análise será apresentada em resultados e discussão.

As temperaturas de trabalho coletadas foram utilizadas como condição de contorno para as simulações computacionais e para os cálculos analíticos.
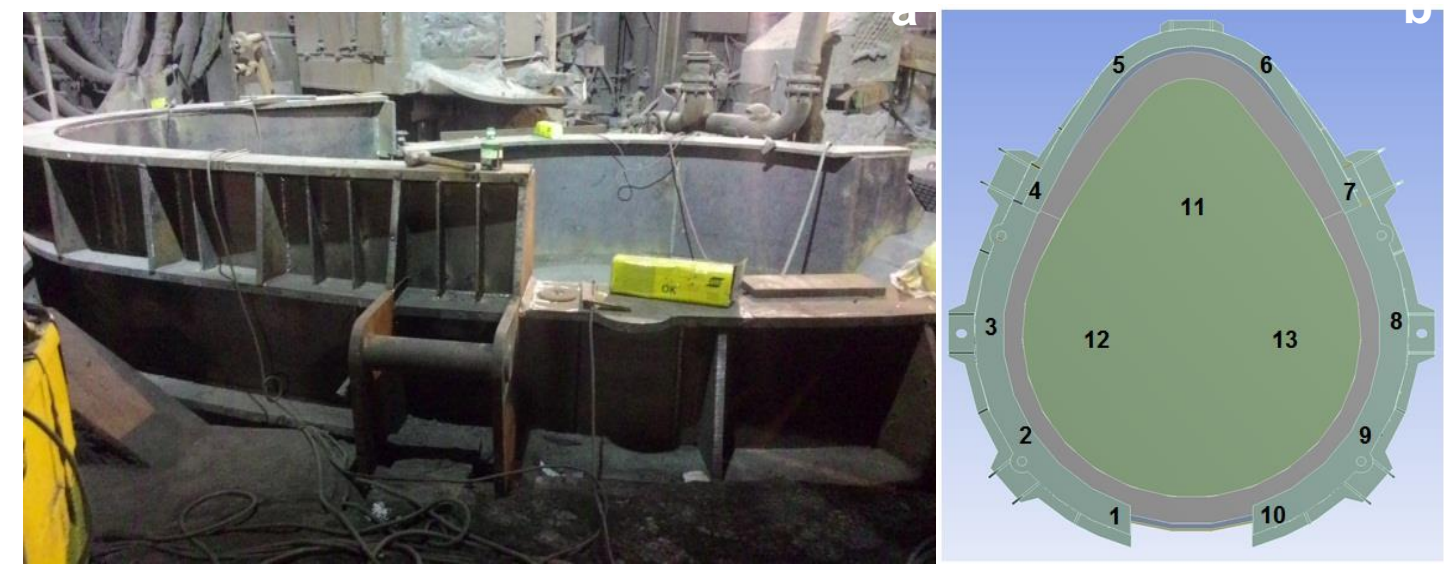

Figura 1. (a) ilustração da região de ponto quente 4; (b) todos 13 pontos analisados ao redor da carcaça.

\subsection{Modelamento matemático}

Considerou-se as taxas de transferência de energia em forma de calor unidimensional e em regime estacionário, como indicado em Gupta [7]. De acordo com Incropera [8] as equações que descrevem a distribuição de temperaturas e perdas de calor na parede do FEA e nas aletas de seção transversal retangular são:

Taxa de transferência de calor unidimensional por condução em paredes compostas (Equação 1):

$$
q_{\text {parede }}=\frac{T_{f q}-T_{c h}}{\frac{\ln \left(\frac{r_{1}}{r_{i}}\right)}{2 \pi L k_{t}}+\frac{\ln \left(\frac{r_{2}}{r_{1}}\right)}{2 \pi L k_{p}}+\frac{\ln \left(\frac{r_{3}}{r_{2}}\right)}{2 \pi L k_{c}}}
$$

Distribuição de temperaturas numa aleta de seção transversal retangular com extremidade perdendo calor por convecção (Equação 2):

$\frac{\theta}{\theta_{b}}=\frac{T-T_{\infty}}{T_{b}-T_{\infty}}=\frac{\cosh m(L-x)+(h / m k) \operatorname{senh} m(L-x)}{\cosh m L+(h / m k) \operatorname{senh} m L}$

Transferência de calor na aleta de seção transversal retangular com extremidade perdendo calor por convecção (Equação 3):

$q_{a, c o n v}=M \frac{\operatorname{senh} m L+(h / m k) \cosh m L}{\cosh m L+(h / m k) \operatorname{senh} m L}$ 
A eficiência do perfil de aleta com seção transversal retangular (Equação 4):

$\eta_{a, c o n v}=\frac{q_{a}}{q_{a, \max }}=\frac{\tanh m L_{c}}{m L_{c}}$

A efetividade da aleta com seção transversal retangular (Equação 5):

$\varepsilon_{a}=\frac{q_{a}}{q_{\text {sem aleta }}}=\frac{q_{a}}{h A_{b} \theta_{b}}$

Onde $T_{f q}$ corresponde à temperatura na face quente e $T_{c h}$ à temperatura na chapa metálica, ambos em Celsius. $R_{i}$ é o raio interno da panela, $R_{1}$ o raio até a face fria do tijolo de trabalho, $R_{2}$ o raio interno da carcaça metálica e $R_{3}$ o raio externo da carcaça metálica, todos em metros. $K_{t}$ é a condutividade térmica do tijolo de trabalho Dolmag100, $K_{p}$ é a condutividade térmica do tijolo permanente - Alukor70 e $K_{c}$ é a condutividade térmica da carcaça metálica - Aço estrutural, todos dados em $\mathrm{W} / \mathrm{m}^{2} \cdot K$ - $L$ representa a espessura em metros, o $\theta_{b}$ é o excesso de temperatura, dado pela diferença de temperatura de uma determinada distância $x$ a partir da base e a temperatura do fluido, $T_{(X)}-T_{\infty}$, o $h$ é chamado de coeficiente de transferência de calor por convecção, dado em $\mathrm{W} / \mathrm{m}^{2} \cdot K, P$ é o perímetro da aleta em contato com o fluido, $k$ é a condutividade térmica do material, $A$ é a área da superfície medida desde a base até uma distância $x, m$ é a relação $(2 h / k t)^{1 / 2}$ e $L_{c}$ é o comprimento da aleta corrigido, para o caso de convecção na extremidade da aleta ele é representado por $L_{c}=L+t / 2$, onde $L$ é o comprimento real da aleta e $t$ a espessura.

Sabendo que o processo de troca de energia térmica por convecção é governado pelo termo $h$, e segundo Holman [9] o valor aproximado do coeficiente de transferência de calor por convecção natural numa placa vertical com $0,3 m$ é igual a $4,5 \mathrm{~W} / \mathrm{m}^{2} \cdot K$, tal valor foi utilizado para os cálculos analíticos.

Os resultados de distribuição de temperatura do revestimento refratário do interior do FEA até a face externa da carcaça são posteriormente comparados com os resultados das simulações computacionais em regime permanente, a fim de validar o mesmo.

\subsection{Desenvolvimento da Simulação Computacional}

Para estimar o calor na peça de trabalho duas técnicas podem ser consideradas. A primeira depende de modelos matemáticos analíticos baseados em equações de calor, envolvendo a solução de equações diferenciais parciais adaptadas e simplificadas, para simular operações práticas. Isso geralmente leva a simplificações significativas nos modelos matemáticos, em geral, devido a geometrias de peças complexas [10]. A segunda técnica é a base computacional para os sistemas de engenharia auxiliada pelo computador e utiliza a Análise de Elementos Finitos, baseada em algumas equações, mais aplicada em elementos pequenos e finitos simples. Quando são juntas, a peça com geometrias complexas pode ser avaliada [11]. Tais técnicas de Elementos Finitos, Diferenças Finitas e Volumes Finitos são largamente empregados para problemas de transferência de calor [12]. 
Para a discretização e simulação computacional do modelo pelo método dos elementos finitos é necessário primeiramente desenvolver-se a geometria tridimensional. Desse modo, a geometria da carcaça inferior do FEA foi desenvolvida baseada no projeto original feito pela empresa alemã Badische Stahl Enginnering $\mathrm{GMBH}$ (BSE), Na Figura 2 pode se observar a geometria original e a geometria proposta com as aletas acrescentadas, respectivamente.
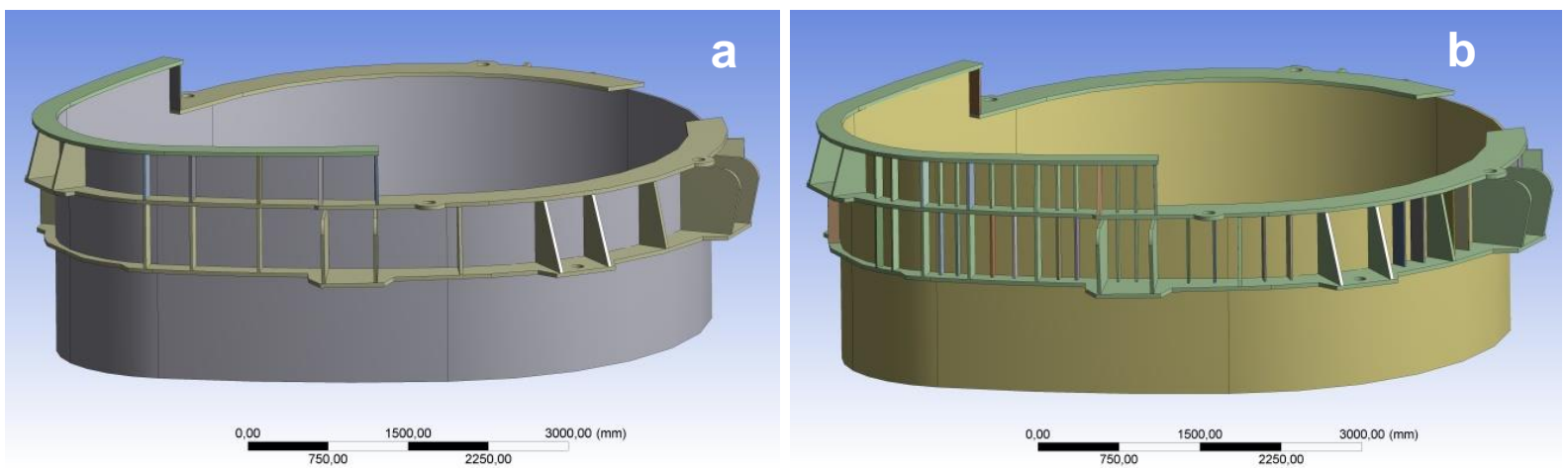

Figura 2. (a) geometria original do FEA; (b) geometria proposta com o acréscimo das aletas.

O software ANSYS (c) foi utilizado para a discretização da geometria e simulação do modelo teórico de fluxo de calor sendo trocado com o fluido de refrigeração por convecção natural e radiação. Os parâmetros de malha para a carcaça proposta foram de 851805 nós e 256314 elementos, sendo de caráter hexaédrica refinada, mostrada na Figura 3. As condições de contorno utilizadas para a simulação térmica foram:

- Regime permanente;

- Condução de calor pelos refratários e chapa metálica;

- Convecção natural e radiação pela chapa metálica em contato com o ar ambiente;

- Temperatura ambiente constante e igual a 50ํㅡ, medida pela câmera termográfica;

- Temperatura do aço líquido igual a $1650^{\circ} \mathrm{C}$;

- Foi modelado o refratário de trabalho com uma espessura de $180 \mathrm{~mm}$, ou seja, final de campanha onde a carcaça metálica esta sujeita as maiores temperaturas de trabalho;

- O coeficiente de condutividade térmica do refratário de trabalho é igual a $4,043 \mathrm{~W} / \mathrm{m} \cdot \mathrm{K}$ e do refratário permanente igual a $2,983 \mathrm{~W} / \mathrm{m} \cdot \mathrm{K}$, ambos foram inseridos durante o pré-processamento;

- O dispositivo utilizado para vazamento do banho metálico não foi modelado. 


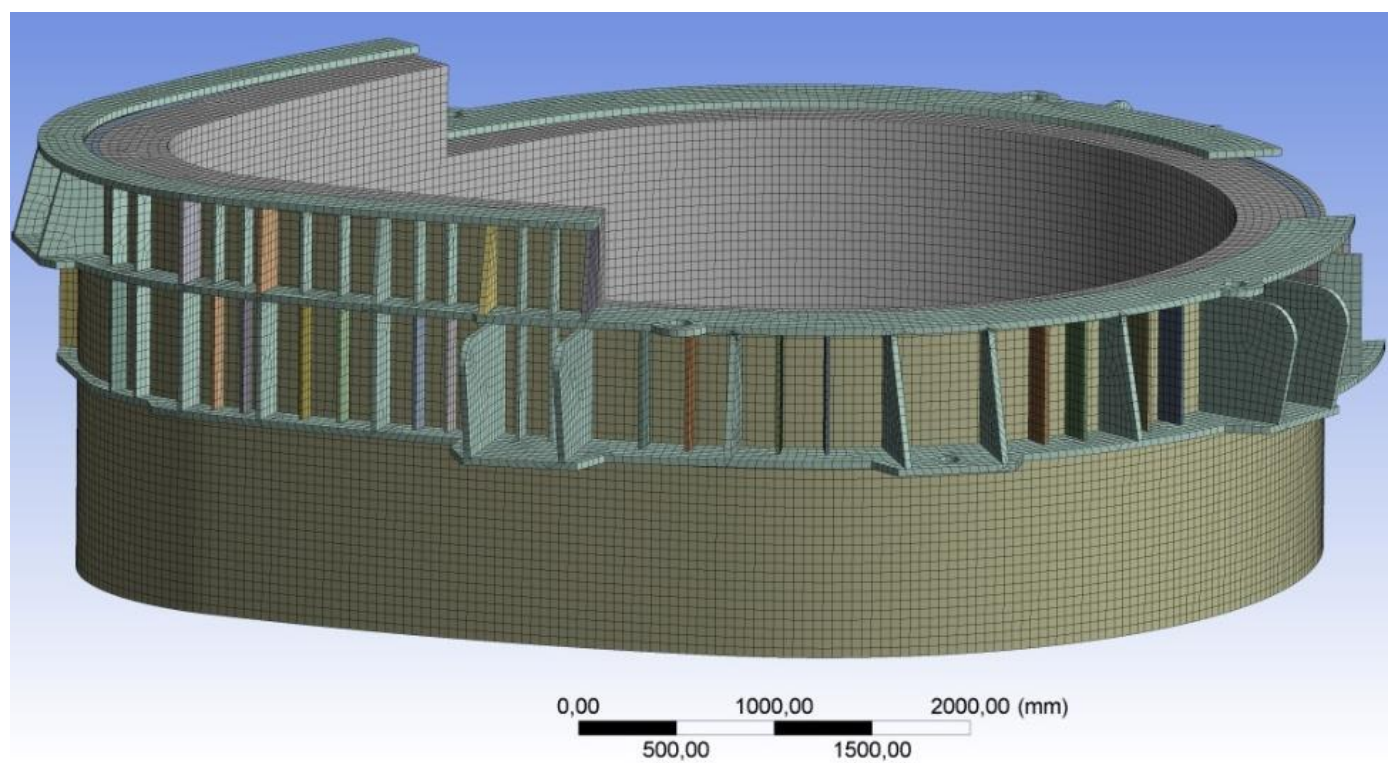

Figura 3. Exemplo de malha detalhada da carcaça inferior do FEA com refratário de trabalho em final de campanha.

Durante a simulação, o primeiro elemento na superfície interna recebe calor por condução simulando a troca térmica entre o aço líquido e o refratário. Todos os outros elementos na parede, superfície da carcaça metálica, trocam calor com o meio ambiente usando o coeficiente de convecção, $h$. Depois de calcular a distribuição de temperatura para todo o domínio, o mesmo procedimento é aplicado ao próximo elemento. Esse procedimento continua seguindo ate seu estado permanente. No final, a distribuição final da temperatura é obtida.

\subsection{Aplicação das aletas}

As aletas foram soldadas na superfície externa da carcaça através do processo MIG/MAG, levando em consideração a composição química do aço que constitui o forno e suas propriedades mecânicas. As aletas acrescentadas são do mesmo aço estrutural que compõe o forno, ASTM A516. Durante a parada programada do dia 15 de agosto 72 aletas foram colocadas ao redor do forno elétrico, Figura 4, distribuídas igualmente entre as nervuras principais de sustentação, cada aleta possuía aproximadamente $450 \mathrm{~mm}$ de altura, $150 \mathrm{~mm}$ de comprimento e 12,7 $\mathrm{mm}$ de espessura.
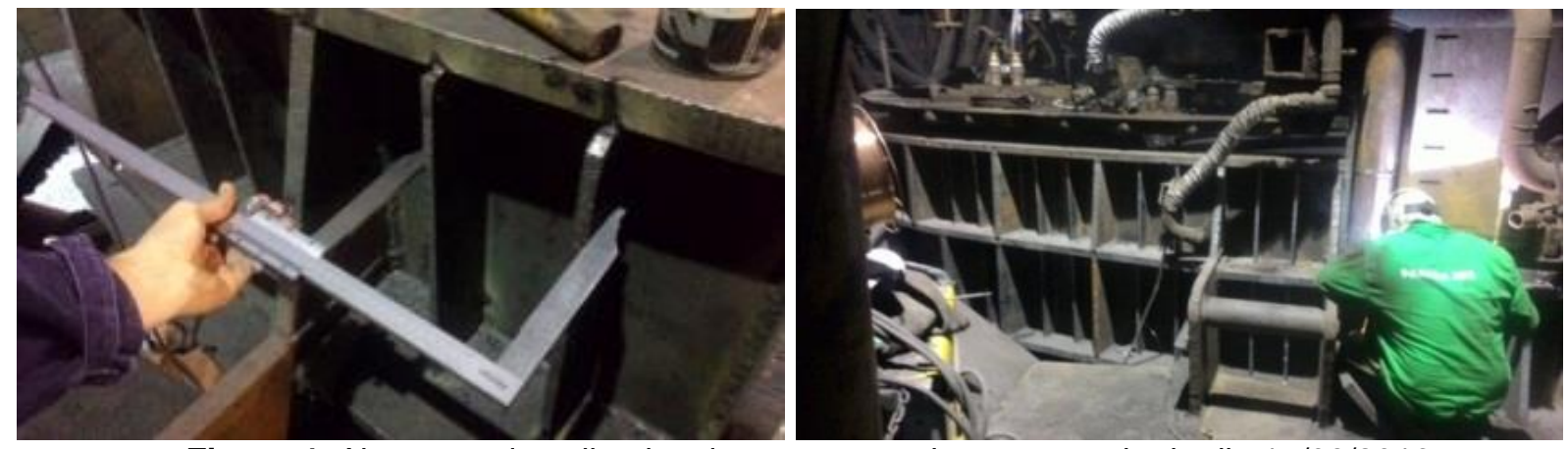

Figura 4. Aletas sendo aplicadas durante a parada programada do dia 15/08/2016.

\section{RESULTADOS E DISCUSSÃO}

\subsection{Temperatura de trabalho da carcaça inferior do FEA}


Como já visto nos métodos, 480 termografias foram analisadas para se obter o perfil térmico de trabalho da carcaça inferior do FEA. As termografias foram tiradas pelos eletricistas de cada turno, como de rotina, e armazenadas nos relatórios diários feitos pelos técnicos operacionais. A média da análise nos 13 pontos distribuídos ao redor da carcaça pode ser vista na Tabela 1.

Tabela 1. Média da temperatura de trabalho em 13 pontos da carcaça inferior do FEA.

\begin{tabular}{ccc}
\hline $\begin{array}{c}\text { Pontos de } \\
\text { análise }\end{array}$ & Região & $\begin{array}{c}\text { Temperatura } \\
\left({ }^{\circ} \mathrm{C}\right)\end{array}$ \\
\hline 1 & Parede & 358 \\
2 & Parede & 293 \\
3 & Parede & 326 \\
4 & Parede & 360 \\
5 & Parede & 296 \\
6 & Parede & 277 \\
7 & Parede & 366 \\
8 & Parede & 350 \\
9 & Parede & 327 \\
10 & Parede & 384 \\
11 & Sola & 302 \\
12 & Sola & 309 \\
13 & Sola & 308 \\
\hline
\end{tabular}

Segundo o AISE Technical Report N 9 a máxima temperatura para a parede de uma panela de aço com 25,4 mm de espessura e capacidade nominal de até $100 \mathrm{t}$ é de $400^{\circ} \mathrm{C}$. Sabendo que a capacidade nominal do FEA é de $45 \mathrm{t}$, a espessura da parede metálica da carcaça é igual a $25,4 \mathrm{~mm}$ e as condições de trabalho se assemelham com de uma panela de aciaria é possível comparar e dizer que, segundo os resultados da análise, as temperaturas de trabalho estão dentro do limite de temperatura. No entanto, vale ressaltar que as medidas foram feitas durante uma campanha onde há um desgaste constante de refratário, ou seja, quanto maior os dias de produção, menor o tamanho do refratário e maior as temperaturas de trabalho do FEA, podendo passar facilmente dos $400^{\circ} \mathrm{C}$.

\subsection{Simulação computacional}

As Figuras 5 e 6 mostram, respectivamente, o perfil de temperatura do revestimento refratário até a face externa da carcaça inferior do FEA, na região do ponto 4, e o fluxo de calor em toda a carcaça inferior do FEA.

Mesmo com aproximações utilizadas na análise de elementos finitos os resultados de temperaturas obtidos foram próximos dos valores encontrados nas medições com a câmera termográfica. Em relação ao ponto 4, com temperatura média de trabalho de $360^{\circ} \mathrm{C}$, essa diferença foi de aproximadamente $25^{\circ} \mathrm{C}$, tal discrepância pode ser explicada pelo fato da média das temperaturas encontradas terem sido analisadas durante uma campanha, ou seja, desde o momento que o refratário estava novo, com espessura de $350 \mathrm{~mm}$, até o seu máximo desgaste, $180 \mathrm{~mm}$, momento que ocorre a preventiva e a troca do mesmo. Enquanto que a simulação computacional só levou em consideração a situação de final de campanha, refratário desgastado. 


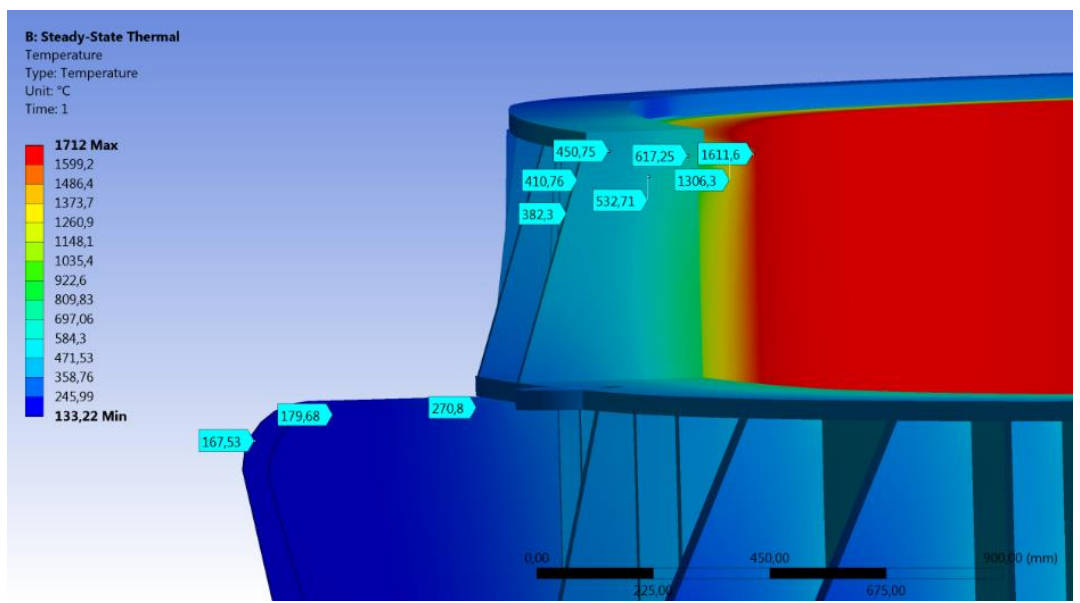

Figura 5. Perfil de temperatura do revestimento refratário até a face externa da carcaça inferior do FEA, na região do ponto 4 .

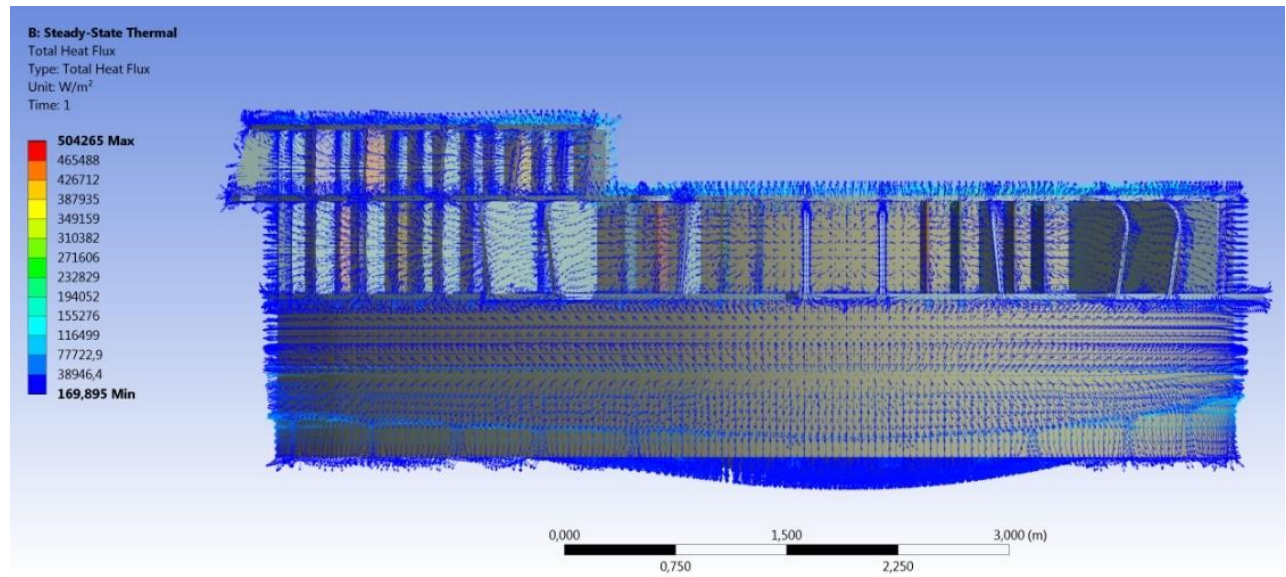

Figura 6. O fluxo de calor em toda a carcaça inferior do FEA.

A Figura 6 mostra uma variação muito grande quanto ao fluxo de calor em toda a carcaça do FEA, mas percebe-se que especialmente nas aletas o fluxo de calor então todos ilustrados de azuis, indicando um valor entre $38946,4 \mathrm{~W} / \mathrm{m}^{2}$ e $77722,9 \mathrm{~W} / \mathrm{m}^{2}$.

As Figuras 7 e 8 mostram, respectivamente, o perfil térmico e o fluxo de calor em cada aleta na região do ponto 4, permitindo uma análise melhor em comparação com a Figura 6. Tanto as temperaturas quanto o fluxo de calor caem à medida que o comprimento das aletas aumenta, semelhante ao modelo de Pedro Bazani Abrahao [13], porém, com aletas de seção transversal retangular.

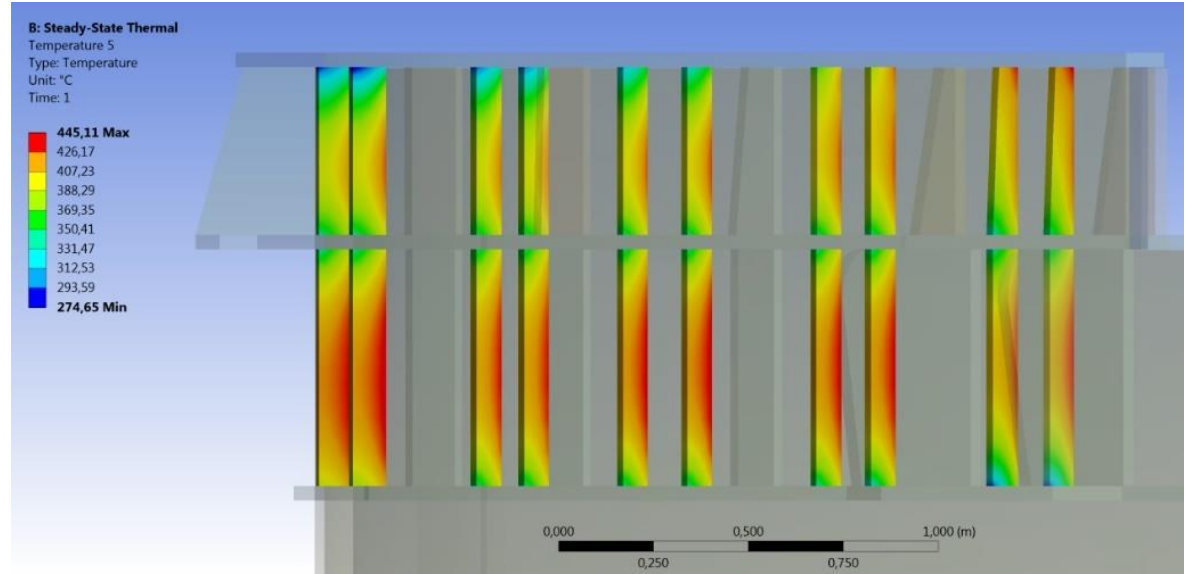

Figura 7. Perfil térmico das aletas da região do ponto 4.

As variações de temperatura e fluxo de calor medidos em cada aleta foram analisadas 
e esclarecidas pela Tabela 2. A tabela está orientada de acordo com as posições das aletas, superior da esquerda para a direita, todas na região do ponto 4.

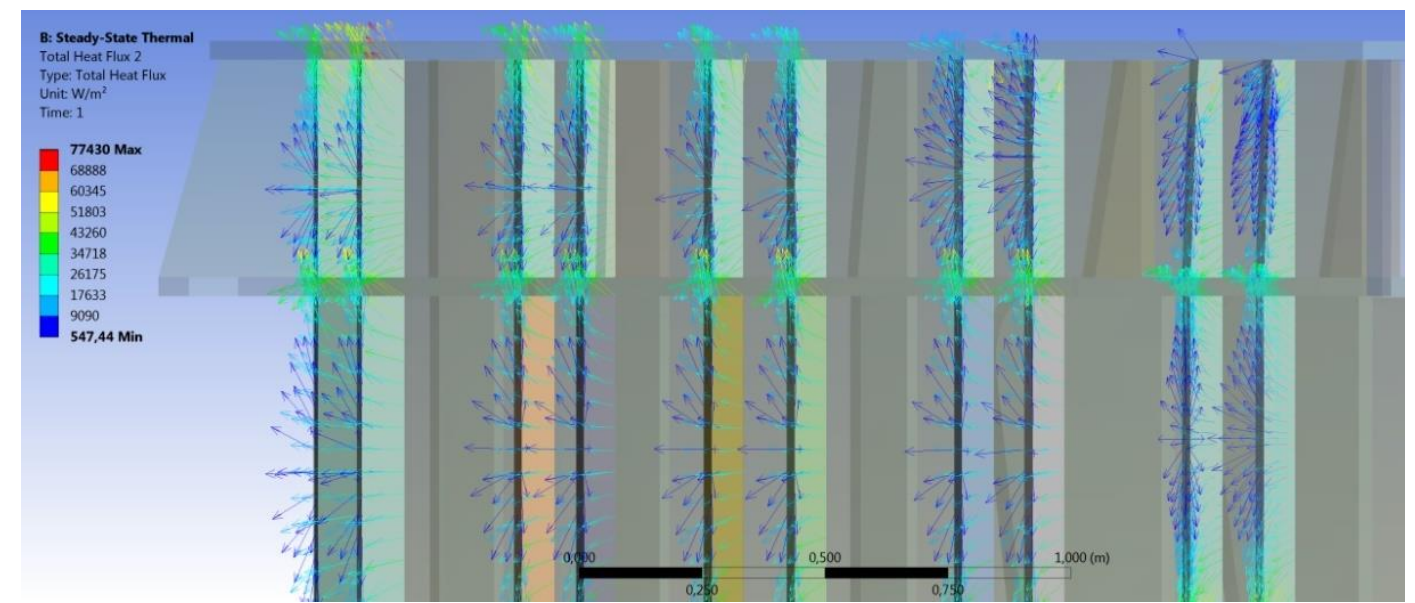

Figura 8. Fluxo de calor em cada aleta na região do ponto 4

Tabela 2. Dados de temperaturas e fluxo de calor das aletas da região do ponto 4 através de simulação computacional.

\begin{tabular}{ccccc}
\hline \multirow{2}{*}{ Número das aletas } & \multicolumn{2}{c}{ Temperatura $\left({ }^{\circ} \mathrm{C}\right)$} & \multicolumn{2}{c}{ Fluxo de calor $\left(\mathrm{W} / \mathrm{m}^{2}\right)$} \\
& Base & Ponta & Base & Ponta \\
\hline 1 & 420,76 & 391,14 & 62386 & 2624,7 \\
2 & 422,39 & 392,62 & 74773 & 2622,5 \\
3 & 420,07 & 392,08 & 60461 & 2648,9 \\
4 & 421,34 & 392,68 & 52650 & 2659,2 \\
5 & 422,69 & 396,51 & 55003 & 2762,2 \\
6 & 426,5 & 398,59 & 53271 & 2976,8 \\
7 & 424,33 & 400,14 & 58387 & 2985,4 \\
8 & 424,27 & 400,7 & 53271 & 2789,9 \\
9 & 417,67 & 390,52 & 60847 & 2935,6 \\
10 & 424,24 & 393,88 & 46234 & 3398,1 \\
11 & 438,16 & 418,41 & 56874 & 2738,1 \\
12 & 440,03 & 417,01 & 54966 & 2718,6 \\
13 & 436,07 & 411,51 & 53906 & 2646 \\
14 & 430,85 & 411,74 & 54400 & 2706,7 \\
15 & 435,66 & 415,63 & 54239 & 2781,7 \\
16 & 439,43 & 416,79 & 56165 & 2681,7 \\
17 & 436,18 & 413,86 & 56768 & 2711,6 \\
18 & 437,72 & 414,54 & 65682 & 2807,8 \\
19 & 430,44 & 406,39 & 59270 & 2694 \\
20 & 433,27 & 410,6 & 65569 & 1937,1 \\
\hline
\end{tabular}

A média do fluxo de calor na base de todas as aletas, onde se tem o maior fluxo de calor, é $57756,1 \mathrm{~W} / \mathrm{m}^{2}$ e na ponta, onde se tem o menor fluxo de calor, é $2741,33 \mathrm{~W} / \mathrm{m}^{2}$, mostrando uma variação discrepante com o aumento de comprimento das aletas. Segundo Incropera [8] esta tendência, do valor de gradiente de temperatura diminuir com o aumento de $x$ é uma consequência da redução da transferência de calor por condução $q_{x}(x)$ devido à contínua perda de calor por 
convecção na superfície da aleta.

\subsection{Resultados analíticos}

Pelas Equações 1 e 2 determinou-se, respectivamente, a perda de calor através do revestimento refratário igual a $23236,34 \mathrm{~W} / \mathrm{m}^{2}$ e o perfil de temperatura desde 0 refratário de trabalho até a ponta da aleta, mostrado no Gráfico 1.

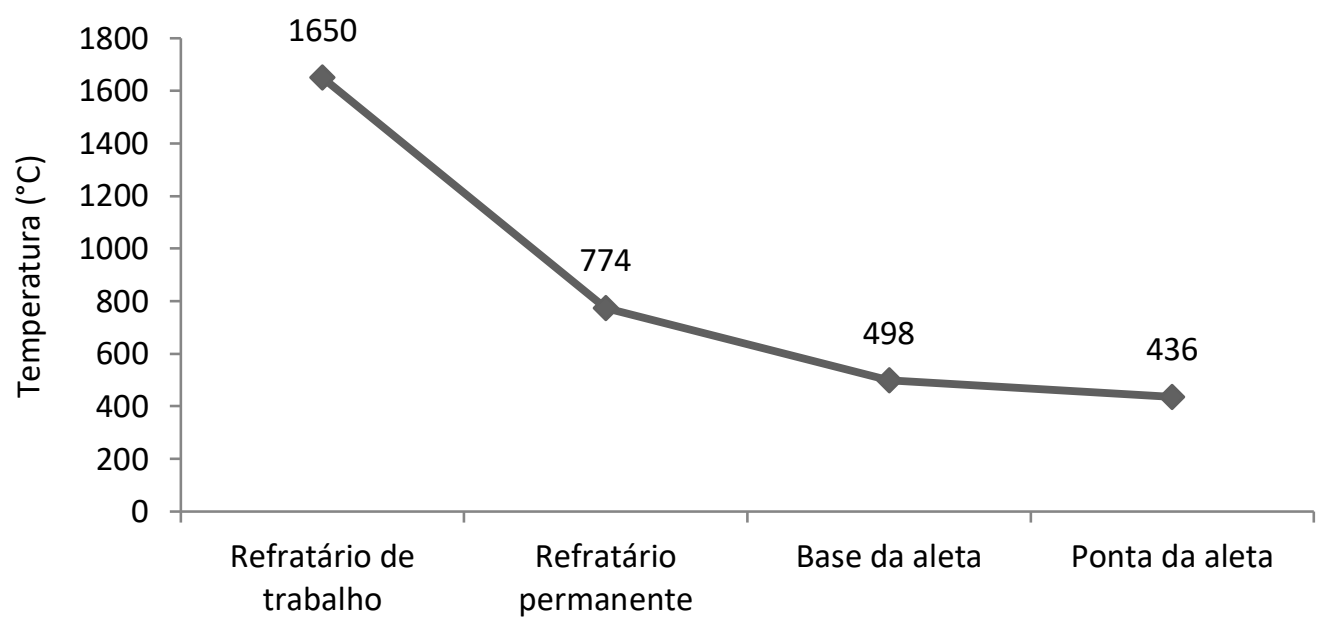

Gráfico 1. Perfil de temperatura desde o refratário de trabalho até a ponta da aleta.

Neste caso, o perfil de temperatura indica que a temperatura na ponta da aleta está acima do indicado pela AISE Technical Report $N^{\circ} 9$ na face externa da carcaça metálica de uma panela. No entanto, sabe-se que a análise foi feita em condições finais de refratário, onde o refratário de trabalho tem seu tamanho mínimo e a temperatura que chega na carcaça metálica é maior.

Pelas Equações 4 e 5 determinou-se a eficiência e a efetividade da aleta, 98\% e 3,9, respectivamente. Um valor de efetividade da aleta igual a um indica que a adição de aletas na superfície não afetou a taxa de transferência de calor, um valor menor que um indica que a aleta está funcionando como isolante, diminuindo a transferência de calor na superfície e um valor de efetividade maior que um significa que as aletas estão aumentando a transferência de calor.

\subsection{Análise das temperaturas da carcaça inferior do FEA após aplicação das aletas.}

Um acompanhamento semelhante ao já citado foi realizado para verificar se o objetivo foi alcançado. No total foram analisadas 46 termografias da região do ponto 4 durante a campanha de outubro e de dezembro, as termografias foram feitas uma por dia, salvo os finais de semanas e feriados. Cada termografia foi tirada no refino secundário, quando a sucata está totalmente fundida e a temperatura de trabalho da carcaça inferior do FEA chega ao seu máximo. Foram consideradas as 26 primeiras termografias da campanha de outubro e as 23 primeiras termografias de dezembro. A primeira parte do acompanhamento iniciou-se no dia 06 de outubro de 2016 antes das aplicações das aletas e terminou no dia 28 de novembro de $2016 \mathrm{com}$ a preventiva. As aletas foram soldadas e a segunda parte do acompanhamento começou no dia 08 de dezembro de 2016 e terminou no dia 11 de janeiro de 2017. 
A partir dos valores encontrados, gerou-se um gráfico comparativo entre as temperaturas de trabalho antes e depois da aplicação das aletas, evidenciado no Gráfico 2.

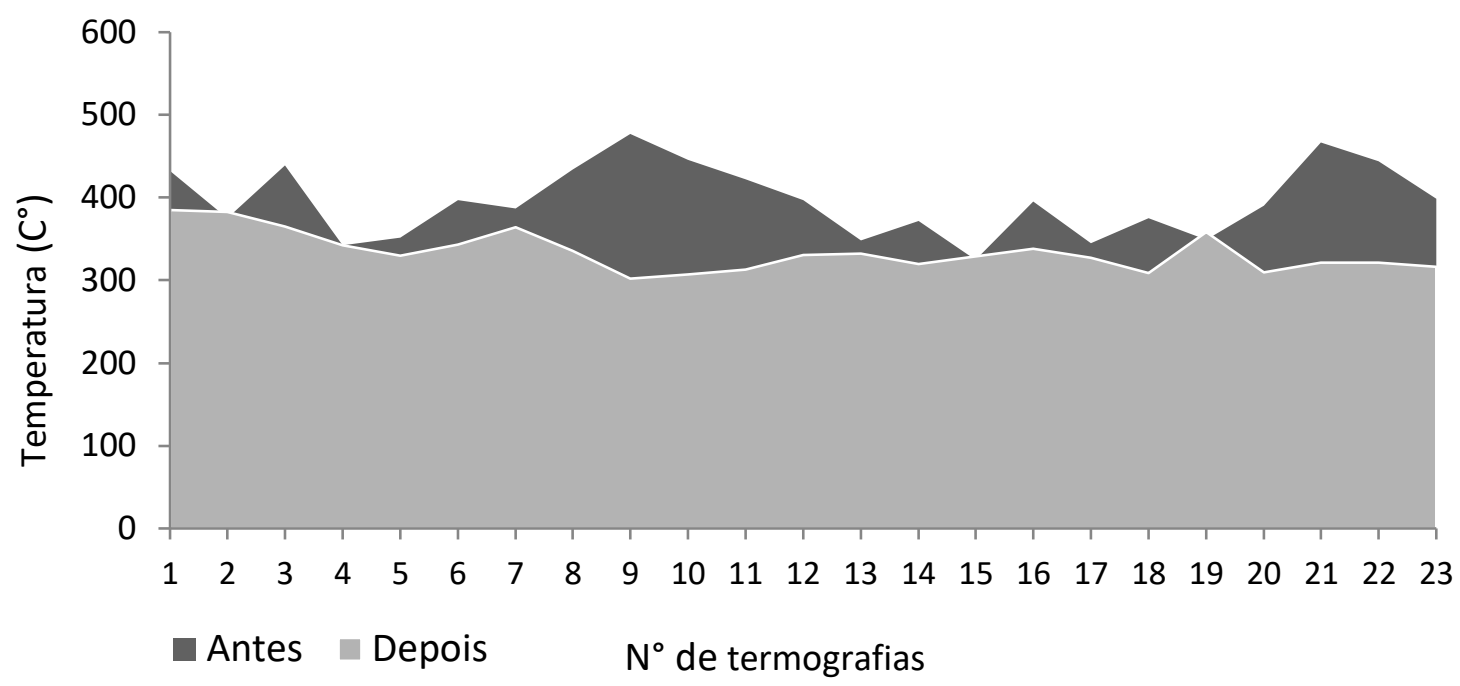

Gráfico 2. Indicador comparativo da temperatura de trabalho na carcaça inferior antes e depois da aplicação das aletas.

Percebe-se que, apesar das variáveis do processo de produção de aço e de erros de medições com a câmera termográfica praticamente todas as medidas de temperaturas durante a análise se encontram inferior depois da aplicação das aletas no ponto 4 e, comparando as médias, há uma queda de $62^{\circ} \mathrm{C}$.

\section{CONCLUSÃO}

- Apesar da diferença de temperatura entre a simulação computacional e as medições experimentais, os dados obtidos através deste trabalho possibilitaram a medição dos parâmetros de desempenho das aletas construídas, como eficiência e efetividade.

- O resultado analítico do fluxo de temperatura do interior do FEA até sua superfície valida os resultados de temperatura da simulação computacional, pois ambos consideraram o revestimento refratário em final de campanha com uma espessura de $180 \mathrm{~mm}$, enquanto que os resultados experimentais com a câmera termográfica analisam a campanha inteira, onde a temperatura de trabalho da carcaça inferior do FEA tende a aumentar com o desgaste do refratário.

- Os resultados de eficiência e efetividade mostram que as aletas são viáveis e estão aumentando consideravelmente a transferência de calor.

- Segundo a análise térmica o objetivo foi cumprido, a temperatura da carcaça inferior do forno elétrico diminuiu significantemente depois da aplicação das aletas, cerca de $60^{\circ} \mathrm{C}$.

\section{Agradecimentos}

Siderúrgica Norte Brasil - Sinobras S.A.

\section{REFERÊNCIAS}


1 Timoshenko N.; Semko A. \& Timoshenko S. Modelling of electric arc furnace offgas remote system. Ironmaking \& Steelmaking. 2014 [acesso em 02 jun. 2017]; 41:257-261. Disponível em: http://dx.doi.org/10.1179/1743281213Y.0000000163.

2 Silva, A. L. da C. Aços E Ligas Especiais. Sumaré, SP: Editora Blücher, 3ed. p491492, 507.

3 Silva, J. N. A. Estudo Teórico E Experimental Do Efeito do Ciclo Térmico No Painel Refrigerado De Forno Elétrico A Arco [tese de mestrado]. Curitiba: Universidade Federal do Paraná, 2014.

4 Duarte, D. F. Estudo, Comparação E Análise Econômica Da Transferência De Calor Em Aletas De Motores Elétricos Fabricados Com Alumínio E Ferro Fundido. In: Associação Brasileira de Engenharia de Produção. Anais do XXXII Encontro Nacional de Engenharia de Produção; 2012; Bento Gonçalves, RS, Brasil.

5 Quites, E. E. C.; Lia, L. R. B. Introdução à Transferência de Calor [trabalho acadêmico]. São Paulo: Universidade Santa Cecília.

6 Silva, A. L. da C. Termodinâmica Aplicada a Aciaria [página da internet]. Volta Redonda [acesso em 21 de mai. 2017]. Disponível em: http://www.equilibrium.trix.net.

7 Gupta, N.; Chandra, S. Temperature Prediction Model for Controlling Casting Superheat Temperature. ISIJ International. 2004 [acesso em 09 jan. 2017]; 44(9): 1517-1526.

Disponível

em: http://dx.doi.org/10.2355/isijinternational.44.1517\%0D.

8 Incropera, F. P.; Dewitt, D. P. Fundamentos de Transferência de Calor e de Massa, 3a edição. LTC - Livros Técnicos e Científicos Editora S. A., R. J. 1990.

9 Holman, J. P. Transferência de Calor. McGraw Hill Book Company, Inc. 1998.

10 Van Els, P. P. D. Desenvolvimento de um Código Computacional Para Solução da Equação de Transferência de Calor Tridimensional Utilizando o Método de Volumes de Controle Baseado em Elementos [trabalho de conclusão de curso]. Brasília: Universidade de Brasília, 2014.

11 Segerlind, L. J. Applied finite elements analysis. New York: John Wiley \& Sons, 2007.

12 Azevedo, Álvaro F.M. Método dos elementos finitos. Cidade do Porto: Faculdade de Engenharia da Universidade do Porto, 2003.

13 Abrahao, P. B. Estudo do Comportamento e Desempenho de Aleta Tipo Pino. Porto Alegre: Universidade Federal do Rio Grande do Sul, 2007. 